\title{
Raman tomography of natural air hydrates
}

\author{
Christian WEIKUSAT, Sepp KIPFSTUHL, Ilka WEIKUSAT \\ Alfred Wegener Institute for Polar and Marine Research, Bremerhaven, Germany \\ Correspondence: Christian Weikusat <christian.weikusat@awi.de>
}

\begin{abstract}
Cryo-Raman tomography allows us, for the first time, to determine accurate morphologies and volumes of natural air hydrates in Antarctic ice cores. The measurements show complex growth structures that are not accounted for by the available models of hydrate formation.
\end{abstract}

KEYWORDS: clathrate hydrates, crystal growth, ice core, ice rheology, paleoclimate

\section{INTRODUCTION}

Polar ice is a composite of ice, air and various impurities of atmospheric origin. This makes ice cores unique climate archives, because the air inclusions in the polar ice sheets are the only direct source for measuring and reconstructing the composition of the atmosphere of the past (e.g. Raynaud and others, 2000). To correctly interpret the findings, a firm understanding of the processes that may be able to change the gas content of the air inclusions is mandatory.

The precursors of polar ice, snow and firn, form a porous permeable material up to $120 \mathrm{~m}$ thick on top of the polar ice sheets. Atmospheric gases circulate through the connected pores and are entrapped at the transition from firn to ice, where the network of open pores closes off to form individual gas inclusions (air bubbles (ABs)) (Schwander and Stauffer, 1984). With time, the ABs move deeper into the ice sheet and start shrinking as the hydrostatic pressure of the overlying ice increases. When the gas pressure inside the $A B$ exceeds the dissociation pressure of hydrate formation the $A B s$ begin to convert to air hydrates (AHs). $\mathrm{AHs}$ are crystalline structures composed of water molecules and containing cavities suitable for housing one or two gas molecules at a time. In contrast to the known phase diagrams (Miller, 1973), AB-AH conversion in polar ice takes place over a large depth range (transition zone) of several hundred meters (Uchida and others, 2014). Microstructure mapping images of the EPICA Dronning Maud Land (EDML) (Antarctica) ice core show first AHs at $\sim 720 \mathrm{~m}$ depth; $\mathrm{ABs}$ were observed to coexist with $\mathrm{AHs}$ down to $\sim 1225 \mathrm{~m}$ depth (Bendel and others, 2013). The widely accepted reason for the thickness of the transition zone is the slow nucleation of hydrates, after which the remaining transition proceeds comparatively quickly (e.g. Shoji and Langway, 1982). This is supported by the fact that no intermediate stages of the $\mathrm{AB}-\mathrm{AH}$ transition have been found in ice cores (Narita and others, 1999; Lipenkov, 2000; Kipfstuhl and others, 2001).

The influence of the $\mathrm{AB}-\mathrm{AH}$ conversion processes on the measured gas contents has been indicated previously: Ikeda and others (1999) and Ikeda-Fukazawa and others (2001) presented results of Raman measurements on individual air inclusions that clearly show gas fractionation in the transition zone, where initial $\mathrm{AHs}$ have lower $\mathrm{N}_{2} / \mathrm{O}_{2}$ ratios (i.e. they are oxygen-enriched) and the late $\mathrm{ABs}$ much higher $\mathrm{N}_{2} / \mathrm{O}_{2}$ ratios (i.e. nitrogen-enriched) than anticipated. Furthermore, anomalies in mixing ratios and isotopic composition of $\mathrm{O}_{2}, \mathrm{~N}_{2}$ and argon were reported by Bender and others (1995). Lüthi and others (2010) showed significant deviations of $\mathrm{CO}_{2}$ and $\mathrm{O}_{2} / \mathrm{N}_{2}$ ratios in and just below the transition zone, that are caused by diffusion and fractionation processes during the $\mathrm{AB}-\mathrm{AH}$ conversion. Little is known about these processes, and while a reduction of resolution in the transition zone helps with measuring $\mathrm{CO}_{2}$, the processes involved have to be understood to ascertain the correct storage of $\mathrm{CO}_{2}$ in the climate archive.

The AHs produced by a direct conversion from $\mathrm{ABs}$ are called primary air hydrates (pAHs) (Kipfstuhl and others, 2001). Two types of this transformation have been proposed by Salamatin and others (1999):

Type A: The hydrate nucleates and rapidly forms a closed hydrate shell, covering the entire bubble wall. In a second, much slower, step the remaining bubble volume is spherically filled with hydrate, where water molecules diffusing through the closed shell towards the growing $\mathrm{AH}$ are the rate-limiting factor.

Type $\mathrm{B}$ : The $\mathrm{AH}$ does not cover the bubble perimeter but proceeds as a flat crystallization front through the $\mathrm{AB}$. Water diffusion through $\mathrm{AH}$ is not needed in this case, which indicates this process is much faster.

Additionally, Kuhs and others (2000) discussed the production of monocrystalline or polycrystalline AHs through a single nucleus or polynucleation respectively. At the beginning of the transition zone, the packing density inside an $\mathrm{AH}$ is much larger than inside a bubble. Therefore, if the $\mathrm{AH}$ growth uses the gas content of the transforming bubble, the resulting $\mathrm{AH}$ will have a significantly smaller volume than the originating bubble. Differences in bubble pressure and diffusion of gases from neighboring bubbles or the ice matrix to the newly forming $\mathrm{AH}$ can influence the actual volume mismatch between $\mathrm{AH}$ and the original bubble (Salamatin and others, 1999), complicating the deduction of bubble radii from $\mathrm{AH}$ sizes.

While most AHs appear smooth-surfaced and very clear (smooth air hydrates, sAHs), AHs with visible structure have been found in all ice cores and have been described as 'cloudy', 'irregular' or 'graupel-like' (Shoji and Langway, 1982; Nakahara and others, 1988; Uchida and others, 1994a; Narita and others, 1999; Pauer and others, 1999, 2000; Lipenkov, 2000; Kipfstuhl and others, 2001). An example from the NorthGRIP ice core is shown in Figure $1 \mathrm{a}$. Carefully chosen illumination conditions reveal threedimensional (3-D) structures inside the pAH (Fig. 1b). The genesis of these structures, which have up to now only been accessible to visual inspection, is still unclear. Salamatin and others (1999) suggested that clusters of structured AHs could represent an $\mathrm{AH}$ shell fragmented by hydrostatic 

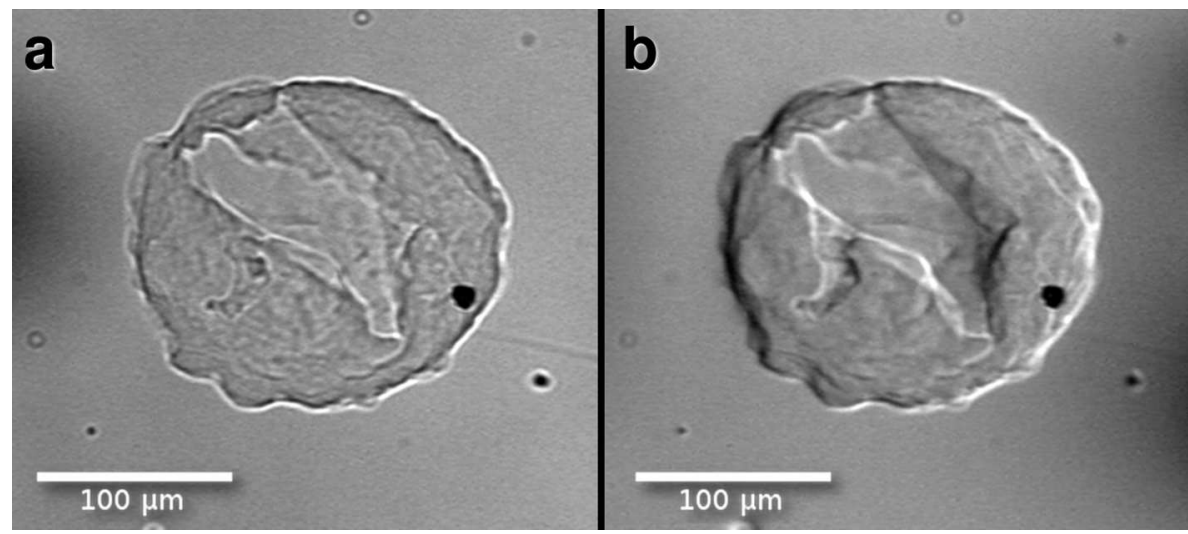

Fig. 1. AH from the NorthGRIP core: (a) transmitted light; (b) asymmetric illumination reveals 3-D structure.

pressure during the type $\mathrm{A} \mathrm{AH}$ growth. The amount of structural data retrievable by microscopic methods is very limited, as no information about the actual 3-D structure can be obtained. While timescales of several thousand years are not adequately reproducible in the laboratory, numerous researchers have performed laboratory experiments on bubble-hydrate conversions (e.g. Uchida and others, 1992, 1994a; Ikeda and others, 1993; Shimada and Hondoh, 2004) and also Raman spectroscopy on synthetic air hydrates (Chazallon and others, 1998). We present for the first time measured data of the intricate 3-D structure of natural air hydrates.

\section{METHODS}

\section{Samples}

We used samples from the EDML ice core from $1005 \mathrm{~m}$, $1048 \mathrm{~m}, 1083 \mathrm{~m}$ and $1084 \mathrm{~m}$ (all depths are inside the transition zone). The EDML core was drilled between 2001 and 2006 at Kohnen Station, Dronning Maud Land, East Antarctica $\left(75^{\circ} 00^{\prime} \mathrm{S}, 0^{\circ} 04^{\prime} \mathrm{E} ; 2882 \mathrm{~m}\right.$ a.s.l.) within the framework of the European Project for Ice Coring in Antarctica (Oerter and others, 2004). The samples studied were drilled in the 2002/03 season and have been stored at $-30^{\circ} \mathrm{C}$ ever since.

The samples were cut, microtomed and sublimated to produce clean surfaces (see Weikusat and others, 2012, for details). Overview images taken with a $10 \times$ lens and the automatic image stitching function of the WITec control software were used to locate suitable $\mathrm{AHs}$ for measurements.

\section{Raman tomography}

The novel Alfred Wegener Institute cryo-Raman system is equipped with fibre optics that allow for a split set-up where the microscope unit is in the cold laboratory and the controller and spectrometer are at room temperature. This set-up eliminates the need for sample transfer between the cold laboratory and a cooling cell mounted to the microscope. As such transfers inevitably expose the samples to large temperature gradients and moisture from the air they have been the most critical point in cryo-analysis. The cryo-Raman set-up allows for sample preparation in the same laboratory where the microscope unit is situated, and transfer to the system is virtually riskless. The set-up also provides much more stable surfaces and reduced sublimation conditions, allowing for long-time measurements of up to several days.
The system consists of a WITec alpha $300 \mathrm{M+}$, UHTS 300 spectrometer using a grating with 600 grooves $\mathrm{mm}^{-1}$, Peltier-cooled CCD detector, frequency-doubled Nd:YAG laser $(532 \mathrm{~nm})$, and Zeiss Epiplan $50 \times$ LWD objective (NA 0.35 ). The laser spot size for this set-up is $\sim 1 \mu \mathrm{m}$, which defines the spatial resolution limit of the measurements. The confocal hole is provided by the diameter of the lighttransmitting fibre from microscope to spectrometer. We used a $100 \mu \mathrm{m}$ fibre which gives a good compromise between confocality and signal intensity. The optical fibre transmitting the laser to the microscope is polarizationmaintaining, while the fibre to the spectrometer depolarizes the light for a better detection efficiency. The temperature in the cold laboratory, and thus the temperature of the sample, were held at $-15^{\circ} \mathrm{C}$ for all measurements.

Hyperspectral large-area stack scans map a rectangular area of the sample at a given step size, where a full spectrum is acquired for each pixel. The microscope turret is then moved a predefined step downwards and another scan with the same parameters is acquired for the new depth. One image is generated from each scan in the stack. These images can then be used to create a 3-D reconstruction of the measured $\mathrm{AH}$.

\section{Data analysis}

The Raman spectra of ice and air hydrate are very similar, both being crystalline structures made from $\mathrm{H}_{2} \mathrm{O}$ molecules (Schicks and others, 2005). Additionally, due to the choice of the $100 \mu \mathrm{m}$ optical fibre and the implied reduced confocality, there is always a small contribution from the ice matrix in every recorded spectrum. The differences used here to distinguish between ice- and air-hydrate phase are shown in Figure 2. The low-energy mode of ice at $\sim 216 \mathrm{~cm}^{-1}$ is shifted $\sim 3 \mathrm{~cm}^{-1}$ to lower values $\left(\sim 213 \mathrm{~cm}^{-1}\right)$ in the hydrate while the band broadens considerably (FWHM (full width at half-maximum) in ice: $\sim 27 \mathrm{~cm}^{-1}$; FWHM in $\mathrm{AH}: \sim 37 \mathrm{~cm}^{-1}$ ). The shoulder at $\sim 290 \mathrm{~cm}^{-1}$ in the ice spectrum is absent from the $\mathrm{AH}$ spectrum. A broadband weighted center-of-mass filter from 180 to $340 \mathrm{~cm}^{-1}$ was used to extract the phase boundaries between ice and air hydrate (WITec Project software). To obtain binary images (Fig. 3), pixels with a value $>250 \mathrm{~cm}^{-1}$ were defined as hydrate, and pixels with lower values as ice. It is important to note that other parameters (e.g. the height of the $\mathrm{O}_{2}$ and $\mathrm{N}_{2}$ bands $\left(\sim 1552 \mathrm{~cm}^{-1}\right.$ and $\left.\sim 2326 \mathrm{~cm}^{-1}\right)$ or shifts in the $\mathrm{OH}$ region $\left.\left(\sim 3000-3600 \mathrm{~cm}^{-1}\right)\right)$ yield the same 


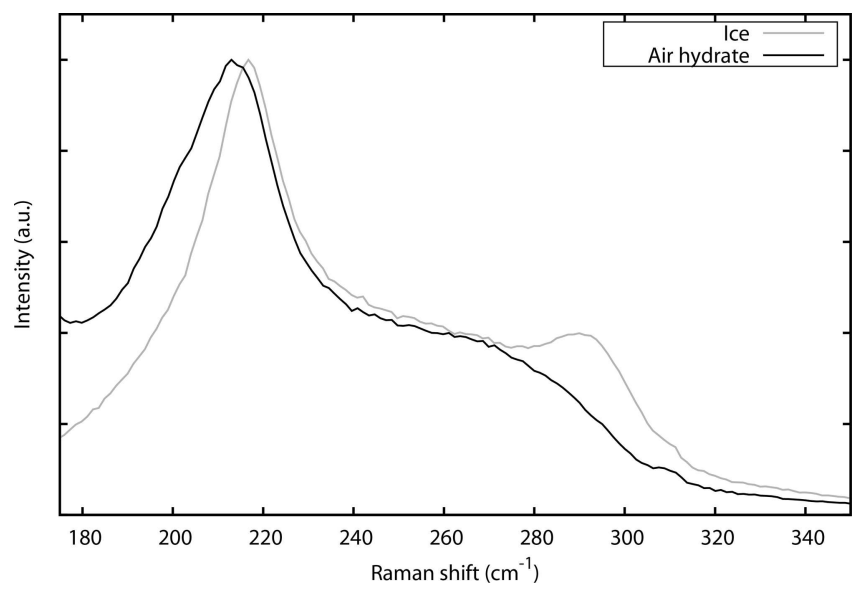

Fig. 2. Differences in the Raman spectra of ice and air hydrate that were used for imaging (averages of 100 spectra with accumulation time of $0.3 \mathrm{~s}$ per spectrum). a.u.: arbitrary units.

results qualitatively, albeit with worse signal/noise ratio. The resulting maps were exported as binary images, with black representing $\mathrm{AH}$ and white, ice. The obtained slices were combined to produce a 3-D reconstruction of the measured $\mathrm{AH}$. Automatic segmentation of the slices and initial mesh generation were performed with Image) (Abràmoff and others, 2004). Smoothing of the initial mesh and calculation of geometric parameters were done with Meshlab (Visual Computing Lab ISTI - CNR, 2013).
Peak fitting and calibration

Background subtraction and fitting of Voigt functions to the Raman bands were done with the open-source software package FITYK 1.2.1 (Wojdyr, 2010). The intensities of the main vibrational bands of $\mathrm{N}_{2}\left(\sim 2326 \mathrm{~cm}^{-1}\right)$ and $\mathrm{O}_{2}$ $\left(\sim 1552 \mathrm{~cm}^{-1}\right)$ were used to calculate $\mathrm{N}_{2} / \mathrm{O}_{2}$ ratios. To calibrate the instrument response, several measurements of room air were averaged, yielding a raw $\mathrm{N}_{2} / \mathrm{O}_{2}$ ratio of $2.97 \pm 0.04$ (mean value and standard deviation of all air measurements). Assuming the laboratory air composition to be $\mathrm{N}_{2} / \mathrm{O}_{2}=3.73$, every calculated ratio was multiplied by a correction factor of 1.26 .

\section{$\mathrm{N}_{2} / \mathrm{O}_{2}$ ratios and crystal orientation}

It has been shown that the intensity of the Raman bands is a function of the orientation of the $\mathrm{AH}$ crystal to the polarization direction of the incident laser (Ikeda and others, 1997). Ikeda and co-workers found values between 8.06 and 10.33 for the $\mathrm{N}_{2} / \mathrm{O}_{2}$ ratios measured at different laser polarization angles for measurements on a well-defined crystal plane of a monocrystalline $\mathrm{AH}$ from the Vostok (East Antarctica) ice core. However, the peaks for $\mathrm{N}_{2}$ and $\mathrm{O}_{2}$ scale homogeneously for most polarization angles (which is reasonable, as they inhabit the same cavities). Additionally, the laser used for this study was only $\sim 90 \%$ polarized and we measured on an arbitrary plane of hydrates, so we assume that the effect is much less pronounced. To be on the safe side we should assume an additional margin of uncertainty of $\sim \pm 1.1$.

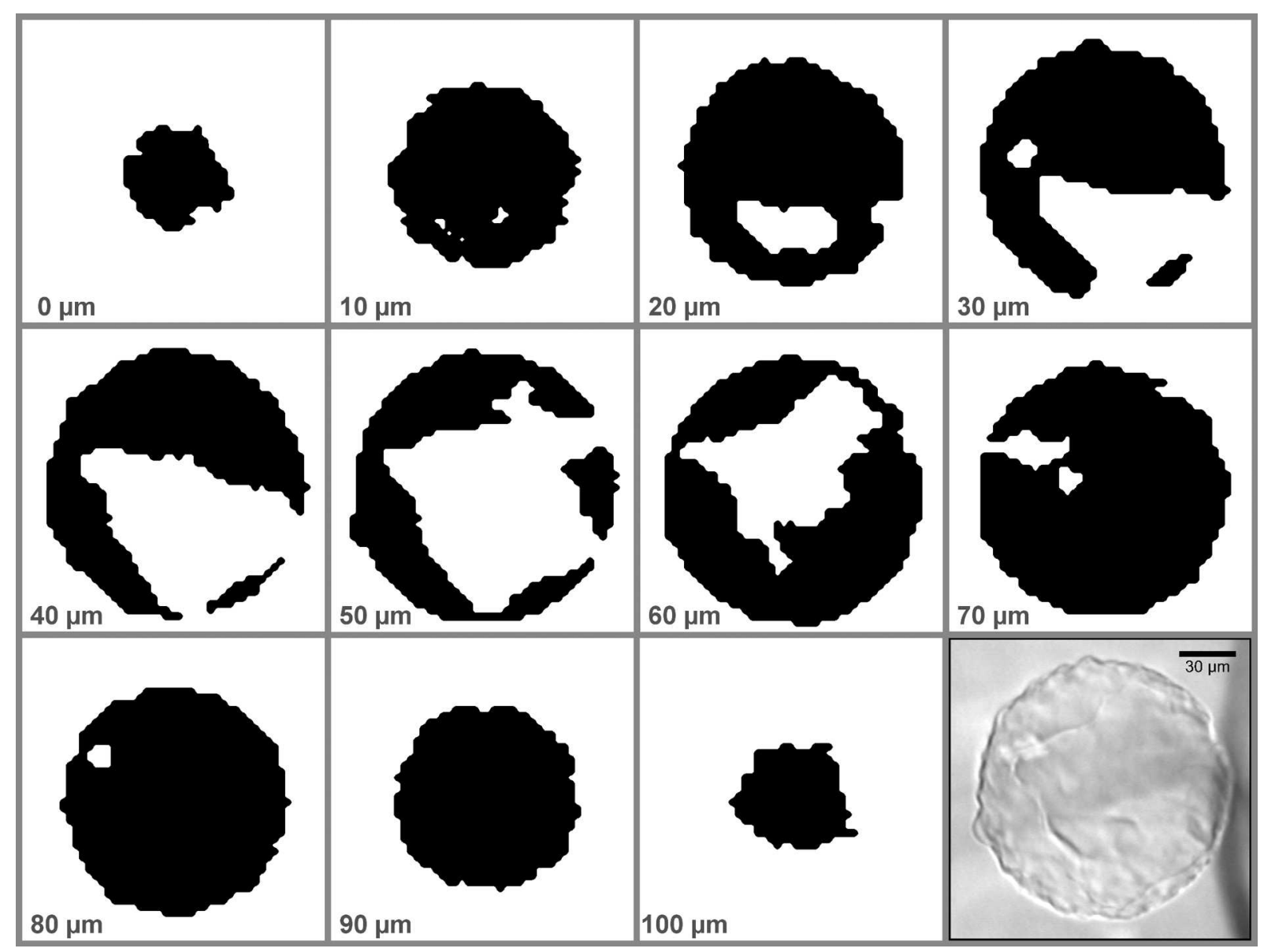

Fig. 3. Binary slices generated from the Raman stack scan of pAH-1 (black: air hydrate; white: ice). The relative depth is given for each image; the scale is given on the photograph (lower right). See Figure 4 for the corresponding 3-D reconstruction. 

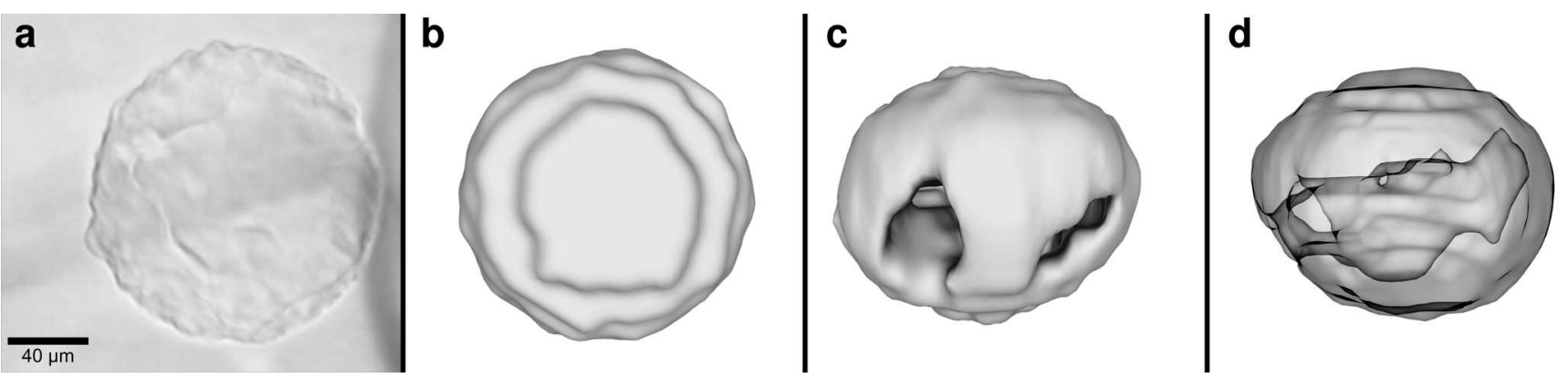

Fig. 4. pAH-1 (depth $1005 \mathrm{~m}$ ). (a) Microscopic image (scale bar for all images). (b) 3-D reconstruction viewed in the same orientation (steps are an artifact of large z-step size). (c) Side view; large holes in the shell are evident. (d) Semi-transparent side view (the holes are to the left) with visible ice intrusion.

\section{RESULTS}

\section{Structure and volumes}

Figure 4a presents a microscopic image of a structured $\mathrm{pAH}$ (pAH-1) from $1005 \mathrm{~m}$ depth. It is almost perfectly round, with a diameter of $\sim 130 \mu \mathrm{m}$. The typical 'cloudy' appearance and rough surface are directly visible. With a step size of $3 \mu \mathrm{m}$ in the $x-y$ plane and a $z$-step size of $10 \mu \mathrm{m}$, the whole stack scan is comprised of 48355 full spectra. An acquisition time of $0.2 \mathrm{~s}$ per spectrum was used, amounting to $\sim 3$ hours total measurement time. The 3 -D reconstruction is shown in Figure $4 \mathrm{~b}-\mathrm{d}$. $\mathrm{pAH}-1$ is not solid but incorporates a large ice intrusion that is connected to the surrounding matrix ice by two holes in the $\mathrm{AH}$ shell (Fig. 4c). The ice volume is asymmetrically distributed inside the $\mathrm{AH}$ (Fig. 4d). The volume of $\mathrm{pAH}-1$ is $9.89 \times 10^{5}{\mu \mathrm{m}^{3}}^{3}$, and the volume of the ice intrusions is $2.12 \times 10^{5} \mu^{3}$ (Fig. $4 d$ ), giving an ice: $\mathrm{AH}$ ratio of 0.2. The combined area of the holes in the $\mathrm{AH}$ shell is $\sim 1687 \mu^{2}$.

Figure 5a shows a microscopic image of a structured $\mathrm{pAH}$ (pAH-2) from $1048 \mathrm{~m}$ depth, exhibiting similar features to pAH-1 (Fig. 4a). The mapped section of the $\mathrm{AH}$ is indicated. The diameter of $\mathrm{pAH}-2$ is $\sim 134 \mu \mathrm{m}$. A volume of $55 \mu \mathrm{m} \times$ $165 \mu \mathrm{m} \times 150 \mu \mathrm{m}$ was scanned with an $x-y$ step size of $2 \mu \mathrm{m}$ and a z-step size of $10 \mu \mathrm{m}$, totaling 34031 full spectra. With an acquisition time of $0.2 \mathrm{~s}$ per spectrum the whole stack took $\sim 2$ hours to complete. Compared to $\mathrm{pAH}-1$, the ice intrusion inside $\mathrm{pAH}-2$ has a more complex structure. Holes in the $\mathrm{AH}$ shell that connect the ice intrusion to the matrix can be seen in Figure $5 \mathrm{~b}$ and $\mathrm{c}$. The $\mathrm{AH}$ volume in this section is $3.45 \times 10^{5} \mu \mathrm{m}^{3}$, and the ice intrusion volume is $1.07 \times 10^{5} \mu \mathrm{m}^{3}$, giving an ice: $\mathrm{AH}$ ratio of 0.31 .
Figure 6a shows two connected $\mathrm{AHs}$ from 1084 m depth: a very clear oval sAH with smooth boundaries (sAH-1) above an irregular and structured $\mathrm{pAH}(\mathrm{pAH}-3)$. Several solid inclusions (black dots) can be seen inside $\mathrm{SAH}-1$. The longest diameter of $\mathrm{sAH}-1$ is $\sim 95 \mu \mathrm{m}$, and the diameter of $\mathrm{pAH}-3$ is $\sim 120 \mu \mathrm{m}$. The scan was done with a step size of $3 \mu \mathrm{m}$ for all three directions, amounting to 212333 full spectra. With an acquisition time of $0.3 \mathrm{~s}$ per spectrum, the total measurement time for the stack was $\sim 18$ hours. The 3 -D reconstruction in Figure $6 \mathrm{~b}$ exhibits a continouus ice intrusion through $\mathrm{pAH}-3$ (the top part of $\mathrm{sAH}-1$ was outside the scan range). Figure $6 \mathrm{c}$ and d clearly show that both $\mathrm{AHs}$ are connected. Figure $6 \mathrm{~d}$ visualizes the dimensions of the ice intrusion through $\mathrm{pAH}-3$. The volume of the ice intrusion is $9.17 \times 10^{4} \mu^{3}$. The volume of $\mathrm{pAH}-3$ could not be calculated reliably due to the connection of both $\mathrm{AHs}$. The volume of the measured connected structure is $1.59 \times 10^{6} \mu \mathrm{m}^{3}$. As the top part of $\mathrm{sAH}-1$ was outside the scan range, this calculation only yields a lower limit for the whole structure.

Figure 7a shows a smooth $\mathrm{AH}$ from $1084 \mathrm{~m}$ depth (sAH2). The scan has a step width of $4 \mu \mathrm{m}$ for all directions and consists of 24000 full spectra. With an acquisition time of $0.3 \mathrm{~s}$ per spectrum the measurement time was $\sim 2$ hours. The 3-D reconstructions (Fig. $7 \mathrm{~b}-\mathrm{d}$ ) show a slightly flattened $\mathrm{AH}$ with smooth outlines and no internal structuration. The volume of $\mathrm{sAH}-2$ is $4.11 \times 10^{6} \mu^{3}$.

Figure 8a shows a faceted sAH from $1084 \mathrm{~m}$ depth (sAH$3)$. The scan has a step size of $3 \mu \mathrm{m}$ for all directions and the stack consists of 23466 full spectra. With an acquisition time of $0.3 \mathrm{~s}$ per spectrum the measurement time was $\sim 2$ hours. Multiple twinned octahedra are visible in the $3-\mathrm{D}$
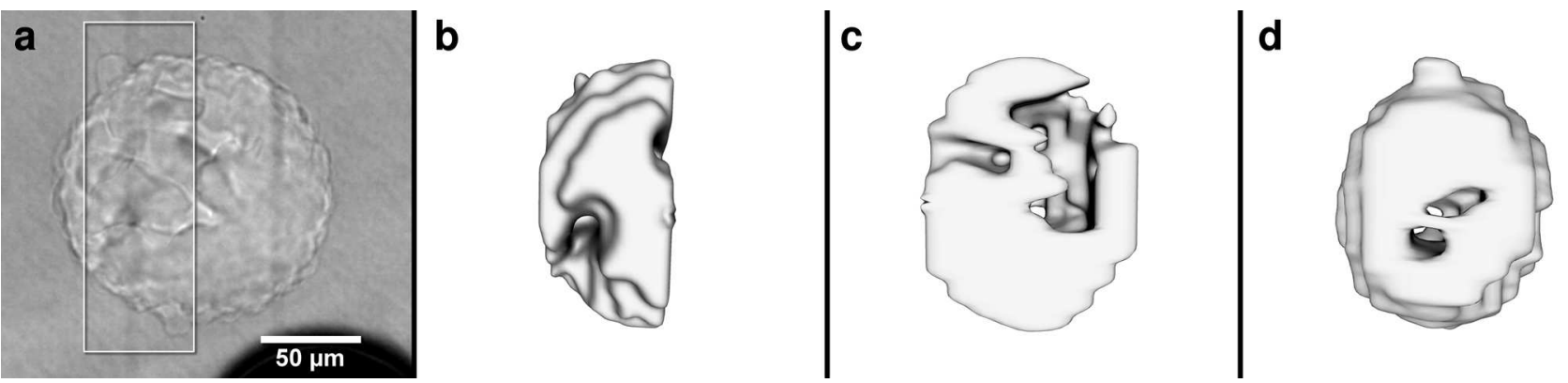

Fig. 5. $\mathrm{pAH}-2$ (depth $1048 \mathrm{~m}$ ). (a) Microscopic image with highlighted scan area (scale bar for all images). (b) 3-D reconstruction viewed in the same orientation (steps are an artifact of large $z$-step size). (c) Side view of the section with evident ice inclusion. (d) Side view from the opposite side. 

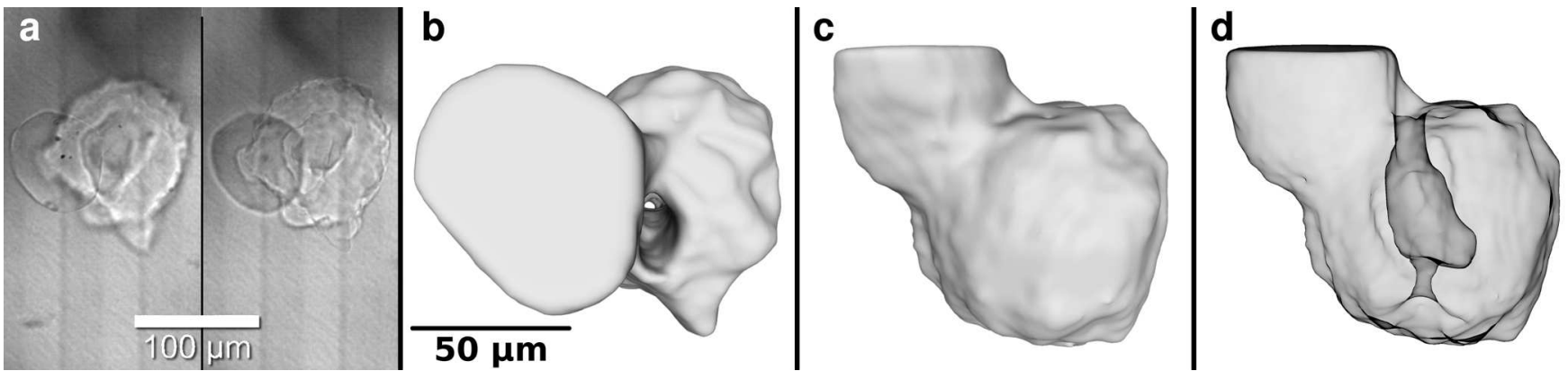

Fig. 6. Connected AHs pAH-3 and sAH-1 (depth $1084 \mathrm{~m}$ ). (a) Microscopic images with focus on sAH-1 (left) and pAH-3 (right). (b) 3-D reconstruction viewed in the same orientation (top part of sAH-1 out of scan range; scale bar for (b-d)). Note the hole through pAH-3. (c) Side view reveals a connection of both AHs. (d) Semi-transparent side view with visible ice intrusion.
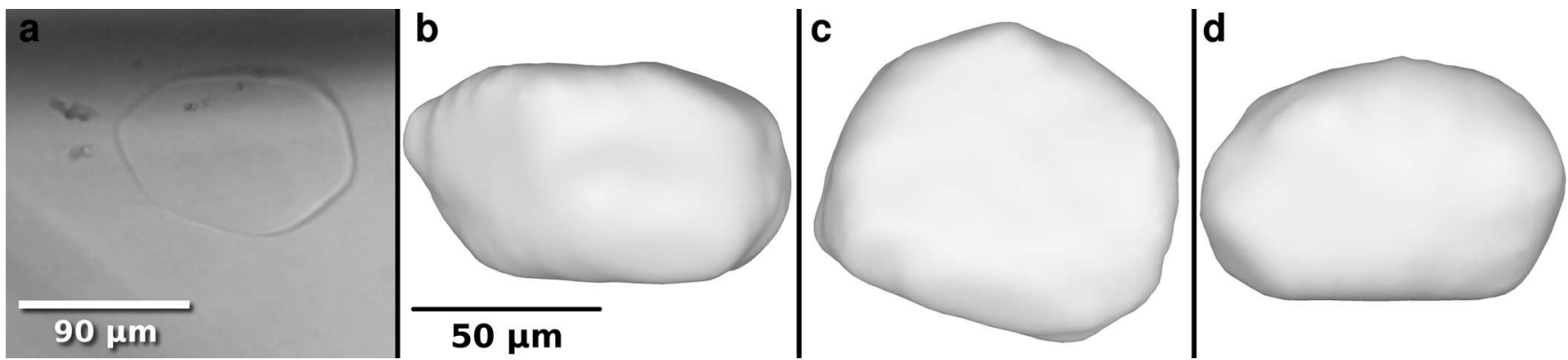

Fig. 7. sAH-2 (depth $1084 \mathrm{~m}$ ). (a) Microscopic image. (b) 3-D reconstruction viewed in the same orientation (scale bar for (b-d)). (c) View perpendicular to (b). (d) View perpendicular to (c).

reconstruction (Fig. $8 \mathrm{~b}-\mathrm{d}$ ). The volume of $\mathrm{sAH}-3$ is $1.12 \times 10^{5} \mu \mathrm{m}^{3}$.

Figure 9a shows a plate-like sAH from $1083 \mathrm{~m}$ depth (sAH-4). The scan step size was $3 \mu \mathrm{m}$ for all directions. With an acqusition time of $0.3 \mathrm{~s}$ per spectrum and a total of 341185 spectra the measurement time was $\sim 28$ hours. The dimensions of $\mathrm{sAH}-4$ are $245 \mu \mathrm{m} \times 125 \mu \mathrm{m} \times 20 \mu \mathrm{m}$; the volume is $6.5 \times 10^{5} \mu \mathrm{m}^{3}$. The lower left part of sAH-4 that appears to be slightly tilted in Figure 9a is only partially connected to the rest of the $\mathrm{AH}$ (Fig. 9c).

\section{$\mathrm{N}_{2} / \mathrm{O}_{2}$ ratios}

To determine $\mathrm{N}_{2} / \mathrm{O}_{2}$ ratios, several spectra were acquired on different points for each $\mathrm{AH}$ and the resulting ratios were averaged. Table 1 shows the results for all presented AHs. The ratio for $\mathrm{pAH}-1$ is $3.60 \pm 0.07$, which is close to the atmospheric value of 3.7. $\mathrm{pAH}-2, \mathrm{pAH}-3$ and $\mathrm{sAH}-1$ are distinctly enriched in nitrogen with ratios of $5.51 \pm 0.15$, $4.84 \pm 0.10$ and $4.91 \pm 0.15$, respectively. The connected $\mathrm{AHs}, \mathrm{pAH}-3$ and sAH-1, exhibit very similar ratios. The solid and smooth sAH-2 has a distinctly higher ratio of $8.30 \pm 0.20$; the plate-like $\mathrm{sAH}-4$ exhibits a similarly high nitrogen content, with an $\mathrm{N}_{2} / \mathrm{O}_{2}$ ratio of $8.09 \pm 0.20$. The highest relative nitrogen content was found in the faceted sAH-3 with an $\mathrm{N}_{2} / \mathrm{O}_{2}$ ratio of $17.49 \pm 0.70$.

The homogeneity of the mixing ratios inside an $\mathrm{AH}$ was checked for $\mathrm{pAH}-1$ by averaging all spectra for each slice and determining the $\mathrm{N}_{2} / \mathrm{O}_{2}$ ratios from the averaged spectra. The values in Table 2 are rather homogeneous and show no systematic alterations with relative depth in the $\mathrm{AH}$.

\section{DISCUSSION}

\section{Structure and formation processes}

The studied pAHs with complex internal structures and incorporated ice bodies are very round and seem to have clearly retained the shape of the originating bubble. A destructive collapse of the $\mathrm{AH}$ shell during growth is certainly more likely to form either irregular agglomerations of splinter-like pieces (as observed by, e.g., Salamatin and
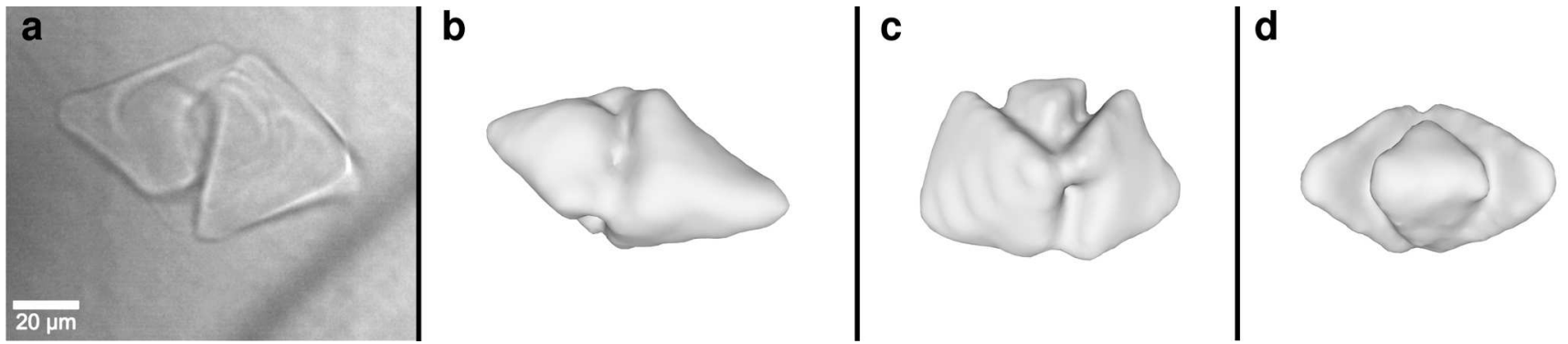

Fig. 8. Faceted $\mathrm{AH}$ (sAH-3, depth $1084 \mathrm{~m}$ ). (a) Microscopic image (scale bar for all images). (b) 3-D reconstruction viewed in the same orientation. (c) View perpendicular to (b). Several twinned octahedra are discernible. (d) View perpendicular to (c). 


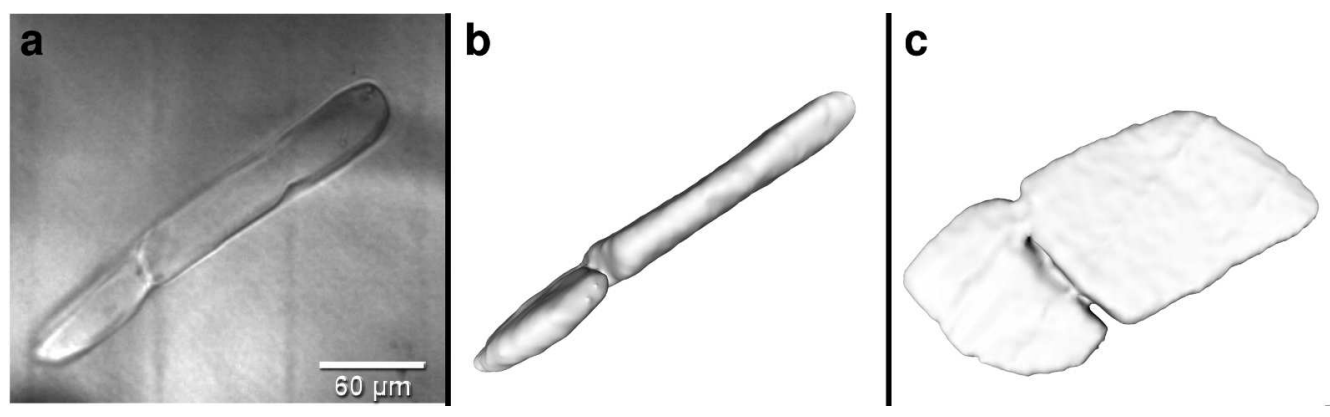

Fig. 9. Plate-like sAH-4 (depth $1083 \mathrm{~m}$ ). (a) Microscopic image (scale bar for all images). (b) 3-D reconstruction viewed in the same orientation. (c) View perpendicular to (b).

others, 1999), or solid, volume-optimized AH bodies (and eventually sAHs), if the process is combined with subsequent recrystallization. We therefore suggest that the intrusion of ice into the former $A B$ volume is a syngenetic and non-destructive process. Salamatin and others (1998) found that the rate-limiting step of post-nucleation $\mathrm{AH}$ conversion is the plastic deformation of the ice- $\mathrm{AH}$ volume around the bubble. They also deduced that $\mathrm{AHs}$ are harder than the surrounding ice. This was later confirmed by Durham and co-workers in a series of ice-hydrate rheology experiments, where both type I and type II hydrates with various guest molecules proved to be up to 20 times harder than ice under identical strain conditions (Durham and others, 2000, 2003, 2005, 2010). We propose the following path for the $\mathrm{AB}-\mathrm{AH}$ transition yielding structured $\mathrm{pAHs}$ : The $\mathrm{AH}$ nuclei start growing into the bubble, without forming a closed hydrate shell around the whole bubble. With proceeding $\mathrm{AH}$ growth the pressure inside the remnant bubble decreases, causing the bubble volume to shrink and the surrounding ice to flow simultaneously into the former bubble volume. In this scenario the diffusion of water molecules is not inhibited by a closed hydrate shell and the whole growth process can happen very fast, similar to the Btype formation described by Salamatin and others (1999), yet the B-type transformation maintains a flattened interface between growing $\mathrm{AH}$ and gas phase throughout the process and should therefore result in solid $\mathrm{AH}$ bodies without internal structures. As AH growth can only continue as long as the bubble pressure is above the dissociation pressure of the $\mathrm{AH}$, the viscosity of the surrounding ice is an important factor for the growth velocity. (If we assume a spherical geometry for the ice intrusion in $\mathrm{pAH}-1$, we can gain a rough estimate for the timescales needed to fill this volume with ice: as a first approximation, we set the driving stress to the hydrostatic pressure, $P=9 \mathrm{MPa}$. The strain rate for single

Table 1. Averaged $\mathrm{N}_{2} / \mathrm{O}_{2}$ ratios and standard deviations

\begin{tabular}{lccr}
\hline Name & $\begin{array}{c}\text { Depth } \\
\mathrm{m}\end{array}$ & Fig. & $\mathrm{N}_{2} / \mathrm{O}_{2}$ ratio \\
& & & \\
\hline $\mathrm{pAH}-1$ & 1005 & 4 & $3.60 \pm 0.07$ \\
$\mathrm{pAH}-2$ & 1048 & 5 & $5.51 \pm 0.15$ \\
$\mathrm{pAH}-3$ & 1084 & 6 & $4.84 \pm 0.10$ \\
$\mathrm{sAH}-1$ & 1084 & 6 & $4.91 \pm 0.15$ \\
$\mathrm{sAH}-2$ & 1084 & 7 & $8.30 \pm 0.20$ \\
$\mathrm{sAH}-3$ & 1084 & 8 & $17.49 \pm 0.70$ \\
$\mathrm{sAH}-4$ & 1083 & 9 & $8.09 \pm 0.20$ \\
& & & \\
\hline
\end{tabular}

crystal ice can then be extracted from figure 2 of Duval and others (1983). As the orientation of the crystallite is unknown, we chose a medium rate of $\dot{\varepsilon}=10^{-5} \mathrm{~s}^{-1}$. To obtain the velocity, we integrated the strain rate, considering only the $x$ direction for further simplification. With $x=110 \mu \mathrm{m}$, ice intrusion volume $V=2.12 \times 10^{5} \mu^{3}$ and opening area of the hydrate shell $A=1687 \mu \mathrm{m}^{2}$, a time of $t=3.2$ hours can be readily calculated. While this may give a lower boundary for the formation of pAH-1, it is by no means intended to represent a mathematical treatment of the microstructural flow of ice, which is well outside the scope of this publication.)

After all gas has been used up for the $\mathrm{AH}$, an ice intrusion remains inside the $\mathrm{AH}$. This process has been witnessed in laboratory experiments, even though the intrusion of ice into the forming hydrate was not recognized at that time (Uchida and others, 1994b; Shimada and Hondoh, 2004). Driven by a thermodynamic urge to reduce the surface energy, the $\mathrm{AH}$ can then recrystallize to form a smooth $\mathrm{AH}$ without internal structuration. The connected AHs seen in Figure 6 are an example of this process, where the $\mathrm{pAH}$ volume is diffusively redistributed in favour of a smooth and compact sAH body. This is further supported by the fact that the $\mathrm{N}_{2} / \mathrm{O}_{2}$ ratios of $\mathrm{pAH}-3$ and $\mathrm{sAH}-1$ are identical in the given error range. The impurities visible in sAH-1 could have acted as nucleation points for the SAH (Ohno and others, 2010). Microscopic images of more AHs undergoing such a metamorphism are provided by Pauer and others (2000). It is

Table 2. $\mathrm{N}_{2} / \mathrm{O}_{2}$ ratios from averaged spectra for each slice of $\mathrm{pAH}-1$ (cf. Fig. 3)

\section{Rel. depth}

$\mathrm{N}_{2} / \mathrm{O}_{2}$ ratio

$\mu \mathrm{m}$

$\begin{array}{lc}0 & 3.54 \\ 10 & 3.63 \\ 20 & 3.57 \\ 30 & 3.64 \\ 40 & 3.69 \\ 50 & 3.65 \\ 60 & 3.64 \\ 70 & 3.54 \\ 80 & 3.48 \\ 90 & 3.53 \\ 100 & 3.69 \\ \text { Average } & \mathbf{3 . 6 0} \pm \mathbf{0 . 0 7} \\ \end{array}$


important to keep in mind that this is not the only process capable of forming smooth $\mathrm{AHs}$; a direct conversion from $\mathrm{AB}$ to $\mathrm{s} \mathrm{AH}$ has been demonstrated in laboratory experiments (Ikeda and others, 1993).

However, the shapes of $\mathrm{sAH}-3$ and $\mathrm{sAH}-4$ are evidently not a product of the above-mentioned processes. $\mathrm{sAH}-3$ exhibits several twinned octahedra that clearly follow the cubic crystal structure of the $\mathrm{AH}$, while sAH-4 closely resembles the so-called plate-like inclusions (PLIs), relaxation features that are known to form on the basal planes of ice crystals, following the hexagonal structure of ice Ih (Nedelcu and others, 2009).

The structured $\mathrm{pAHs}$ with ice intrusions are more susceptible to mechanical destruction than solid AHs. The frequently seen clusters of small $\mathrm{AHs}$, described by Salamatin and others (1999) as a product of a collapsing $\mathrm{AH}$ shell during transition, could also have been formed by post-genetic separation due to ice deformation.

\section{$\mathrm{N}_{2} / \mathrm{O}_{2}$ ratios}

With the exception of $\mathrm{pAH}-1$, which has a ratio close to the atmospheric value, all $\mathrm{AHs}$ measured for this study are enriched in nitrogen. This is contrary to other works that found the $\mathrm{AHs}$ in the transition zone of Dome Fuji, Antarctica, to be oxygen-enriched (Ikeda and others, 1999; Ikeda-Fukazawa and others, 2001). However, it has also been shown that $\mathrm{ABs}$ in the transition zone are enriched in nitrogen: Weikusat and others (2012) reported $\mathrm{N}_{2} / \mathrm{O}_{2}$ values up to 6 for EDML while Ikeda-Fukazawa and others (2001) found extreme values up to 14 in the Vostok core. As all ABs will have transformed by the end of the transition zone, it seems likely that the $\mathrm{N}_{2} / \mathrm{O}_{2}$ ratios measured in the $\mathrm{AHs}$ are due to the conversion from already nitrogen-enriched $\mathrm{ABs}$. Exceptionally high $\mathrm{N}_{2} / \mathrm{O}_{2}$ ratios as measured in $\mathrm{sAH}-2$ (8.30), sAH-4 (8.09) and sAH-3 (17.49) could also indicate a different path of hydrate formation, not necessarily implying equally nitrogen-enriched $\mathrm{ABs}$. For $\mathrm{sAH}-3$ and $\mathrm{sAH}-4$, this is supported by the unusual morphologies, which are clearly not derived from a common air bubble. It is also worth noting that the solid $\mathrm{AHs}$ without ice intrusions investigated in this study show higher $\mathrm{N}_{2} / \mathrm{O}_{2}$ ratios than the cloudy pAHs, yet more data are needed for a statistical evaluation. Selective gas losses during the long storage time could also have altered the measured mixing ratios. A detailed interpretation of these unusually high values is outside the scope of this work and will be addressed in a dedicated publication.

\section{CONCLUSION}

The structured pAHs are a result of a fast conversion process, where the $\mathrm{AH}$ shell is not closed at any time and thus a fast conversion is possible during the whole process. Ice from the surrounding matrix flows to intrude the former $\mathrm{AB}$ volume, keeping the pressure in the remnant bubble above the $\mathrm{AH}$ dissociation pressure. The flow velocity is then an important factor for the conversion. On the microscale, the flow can be very fast (hours) and would therefore be on the same timescales as the formation processes seen in laboratory experiments (Uchida and others, 1992, 1994a; Ikeda and others, 1993; Shimada and Hondoh, 2004). The constant contact to the ice matrix also eliminates the need for (slow) diffusion of water molecules through the $\mathrm{AH}$ layer.
Detailed investigations and modelling of the processes with a suitable tool (e.g. ELLE; Bons and others, 2008) could yield information about deformation and strain distribution on the microscale.

\section{ACKNOWLEDGEMENTS}

We thank Daniela Jansen for fruitful discussions, and three anonymous reviewers for helpful comments and suggestions. This work was supported by the Deutsche Forschungsgemeinschaft (DFG) in the framework of the priority programme 'Antarctic Research with comparative investigations in Arctic ice areas' by grant DFG WE4771 (CW) and by the Helmholtz Association by YIG grant VH-NG-802 (IW).

\section{REFERENCES}

Abràmoff MD, Magalhães PJ and Ram SJ (2004) Image processing with ImageJ. Biophoton. Int., 11, 36-42

Bendel $V$ and 6 others (2013) High-resolution variations in size, number and arrangement of air bubbles in the EPICA DML (Antarctica) ice core. J. Glaciol., 59(217), 972-980 (doi: 10.3189/2013JoG12J245)

Bender ML, Sowers T and Lipenkov V (1995) On the concentrations of $\mathrm{O}_{2}, \mathrm{~N}_{2}$, and $\mathrm{Ar}$ in trapped gases from ice cores. J. Geophys. Res., 100, 18651-18660

Bons P, Köhn D and Jessel M (2008) Microdynamic simulation from microprocess to patterns in rocks. (Volume 106 of Lecture Notes in Earth Sciences) Springer, Berlin

Chazallon B, Champagnon B, Panczer G, Pauer F, Klapproth A and Kuhs W (1998) Micro-Raman analysis of synthetic air clathrates. Eur. J. Mineral., 10, 1125-1134

Durham WB, Kirby SH and Stern LA (2000) Comparative rheologies of solid $\mathrm{H}_{2} \mathrm{O}, \mathrm{CO}_{2}$, and $\mathrm{CO}_{2}$ clathrate hydrate. In Proceedings of the 2nd International Conference on Mars Polar Science and Exploration, 21-25 August 2000, Reykjavik, Iceland. Lunar and Planetary Institute, Houston, TX

Durham W, Kirby S, Stern L and Zhang W (2003) The strength and rheology of methane clathrate hydrate. J. Geophys. Res., 108 (doi: 10.1029/2002JB001872)

Durham W, Stern L, Kirby S and Circone S (2005) Rheological comparisons and structural imaging of sl and sll endmember gas hydrates and hydrate/sediment aggregates. In Proceedings of the 5th International Conference on Gas Hydrates, Trondheim, Norway, June 2005. Tapir Academic Press, Trondheim

Durham W, Prieto-Ballesteros O, Goldsby DL and Kargel JS (2010) Rheological and thermal properties of icy materials. Space Sci. Rev., 153(1-4), 273-298 (doi: 10.1007/s11214-009-9619-1)

Duval P, Ashby MF and Anderman I (1983) Rate-controlllng processes in the creep of polycrystalline ice. J. Phys. Chem., 87, 4066-4074

Ikeda T, Uchida T and Mae S (1993) The effect of hydrostatic pressure on the formation of air-hydrate crystals. In Proceedings of the NIPR Symposium on Polar Meteorology and Glaciology 7. National Institute of Polar Research, Tokyo

Ikeda T, Fukazawa H, Mae S, Hondoh T and Langway CC Jr (1997) Crystal-orientation dependence of Raman spectra of natural air hydrate single crystal. J. Phys. Chem. B, 101, 6180-6183

Ikeda T and 7 others (1999) Extreme fractionation of gases caused by formation of clathrate hydrates in Vostok Antarctic ice. Geophys. Res. Lett., 26, 91-94

Ikeda-Fukazawa T, Hondoh T, Fukumura T, Fukazawa $\mathrm{H}$ and Mae $\mathrm{S}$ (2001) Variation in $\mathrm{N}_{2} / \mathrm{O}_{2}$ ratio of occluded air in Dome Fuji Antarctic ice. J. Geophys. Res., 106, 17 799-17810

Kipfstuhl S, Pauer F, Kuhs WF and Shoji H (2001) Air bubbles and clathrate hydrates in the transition zone of the NGRIP deep ice core. Geophys. Res. Lett., 28, 591-594 
Kuhs WF, Klapproth A and Chazallon B (2000) Chemical physics of air clathrate hydrates. In Hondoh T ed. Physics of ice core records. Hokkaido University Press, Sapporo, 373-392

Lipenkov VY (2000) Air bubbles and air-hydrate crystals in the Vostok ice core. In Hondoh T ed. Physics of ice core records. Hokkaido University Press, Sapporo, 327-358

Lüthi $\mathrm{D}$ and 11 others (2010) $\mathrm{CO}_{2}$ and $\mathrm{O}_{2} / \mathrm{N}_{2}$ variations in and just below the bubble-clathrate transformation zone of Antarctic ice cores. Earth Planet. Sci. Lett., 297, 226-233 (doi: 10.1016/j.epsl. 2010.06.023)

Miller SL (1973) The clathrate hydrates - their nature and occurrence. In Whalley E, Jones SJ and Gold LW eds Physics and chemistry of ice: papers presented at the Symposium on the Physics and Chemistry of Ice, held in Ottawa, Canada, 14-18 August 1972. Royal Society of Canada, Ottawa

Nakahara J, Shigesato Y, Higashi A, Hondoh T and Langway CC Jr (1988) Raman spectra of natural clathrates in deep ice cores. Philos. Mag. B, 57, 421-430 (doi: 10.1080/ 13642818808208514)

Narita H and 8 others (1999) Characteristics of air bubbles and hydrates in the Dome Fuji ice core, Antarctica. Ann. Glaciol., 29, 207-210

Nedelcu AF, Faria SH and Kuhs W (2009) Correspondence. Raman spectra of plate-like inclusions in the EPICA-DML (Antarctica) ice core. J. Glaciol., 55, 183-184 (doi: 10.3189/ 002214309788609010)

Oerter H, Graf W, Meyer H and Wilhelms F (2004) The EPICA ice core from Dronning Maud Land: first results from stable-isotope measurements. Ann. Glaciol., 39, 307-312 (doi: 10.3189/ 172756404781814032)

Ohno H, Lipenkov VY and Hondoh T (2010) Formation of air clathrate hydrates in polar ice sheets: heterogeneous nucleation induced by micro-inclusions. J. Glaciol., 56, 917-921 (doi: 10.3189/002214310794457317)

Pauer F, Kipfstuhl S, Kuhs WF and Shoji H (1999) Air clathrate crystals from the GRIP deep ice core, Greenland: a number-, size- and shape-distribution study. J. Glaciol., 45, 22-30

Pauer F, Kipfstuhl S, Kuhs WF and Shoji H (2000) Classification of air clathrates found in polar ice sheets. Polarforschung, 66, 31-38

Raynaud D, Barnola JJ-M, Chappellaz J, Blunier T, Indermühle A and Stauffer B (2000) The ice record of greenhouse gases: a view in the context of future changes. Quat. Sci. Rev., 19, 9-17
Salamatin AN, Hondoh T, Uchida T and Lipenkov VY (1998) Postnucleation conversion of an air bubble to clathrate air-hydrate crystal in ice. J. Cryst. Growth, 193, 197-218

Salamatin AN, Lipenkov VY, Hondoh T and Ikeda T (1999) Simulated features of the air-hydrate formation process in the Antarctic ice sheet at Vostok. Ann. Glaciol., 29, 191-201

Schicks JM, Erzinger J and Ziemann MA (2005) Raman spectra of gas hydrates - differences and analogies to ice Ih and (gas saturated) water. Spectrochim. Acta, 61, 2399-2403 (doi: 10.1016/j.saa.2005.02.019)

Schwander J and Stauffer B (1984) Age difference between polar ice and the air trapped in its bubbles. Nature, 311, 45-47

Shimada W and Hondoh T (2004) In situ observation of the transformation from air bubbles to air clathrate hydrate crystals using a Mizuho ice core. J. Cryst. Growth, 265, 309-317 (doi: 10.1016/j.jcrysgro.2004.01.040)

Shoji $\mathrm{H}$ and Langway CC Jr (1982) Air hydrate inclusions in fresh ice core. Nature, 298, 548-550

Uchida T, Hondoh T, Mae S, Duval P and Lipenkov VY (1992) Insitu observations of growth process of clathrate air-hydrates under hydrostatic pressure. In Maeno $\mathrm{N}$ and Hondoh $\mathrm{T}$ eds Physics and chemistry of ice. Hokkaido University Press, Sapporo

Uchida T, Hondoh T, Mae S, Lipenkov VY and Duval P (1994a) Airhydrate crystals in deep ice-core samples from Vostok Station, Antarctica. J. Glaciol., 40, 79-86

Uchida T, Hondoh T, Mae S, Duval P and Lipenkov VY (1994b) Effects of temperature and pressure on the transformation rate from air bubbles to air-hydrate crystals in ice sheets. Ann. Glaciol., 20, 143-147

Uchida T, Yasuda K, Oto Y, Shen R and Ohmura R (2014) Natural supersaturation conditions needed for nucleation of air-clathrate hydrates in deep ice sheets. J. Glaciol., 60(224), 1111-1116 (doi: 10.3189/2014JoG13J232)

Visual Computing Lab ISTI - CNR (2013) Meshlab. http://meshlab. sourceforge.net/

Weikusat C, Freitag J and Kipfstuhl S (2012) Raman spectroscopy of gaseous inclusions in EDML ice core: first results microbubbles. J. Glaciol., 58, 761-766 (doi: 10.3189/ 2012JoG11J222)

Wojdyr M (2010) Fityk: a general-purpose peak fitting program. J. Appl. Cryst., 43, 1126-1128 (doi: 10.1107/ S0021889810030499) 